VIEIRA, R.F.; OLIVEIRA, V.R.; VIEIRA, C. Cultivo do feijão-mungo-verde no verão em Viçosa e em Prudente de Morais. Horticultura Brasileira, Brasília, v. 21, n. 1, p. 37-43, março 2003.

\title{
Cultivo do feijão-mungo-verde no verão em Viçosa e em Prudente de Morais
}

\author{
Rogério F. Vieira ${ }^{1}$; Valter R. Oliveira ${ }^{2}$; Clibas Vieira ${ }^{3}$ \\ ${ }^{1}$ Epamig, C. Postal 216, 36.571-000 Viçosa-MG; ${ }^{2}$ Embrapa Hortaliças, C. Postal 218, 70.359-970 Brasília-DF; ${ }^{3}$ Dep $^{\text {to }}$ de Fitotecnia, UFV, \\ 36.571-000 Viçosa-MG; E-mail: rfvieira@homenet.com.br; valter@cnph.embrapa.br
}

\section{RESUMO}

Foram avaliados no verão, 25 genótipos de feijão-mungo-verde em Viçosa (plantio em dezembro de 1997) e em Prudente de Morais (plantio em janeiro de 1999) (MG): dezenove linhagens do "Asian Vegetable Research Development Center", quatro do Instituto Nacional de Pesquisa da Amazônia, uma cultivar de origem peruana além da cv. Ouro Verde. Utilizou-se o delineamento experimental em blocos ao acaso, com três repetições. Os rendimentos variaram de 1,2 a 2,0 t/ha em Viçosa e de 1,3 a 2,6 t/ha em Prudente de Morais. Muitas linhagens renderam mais que a cultivar Ouro Verde, destacando-se a 'VC 3984-B-2-B-4-1-B' pela resistência ao acamamento. O feijãomungo-verde mostrou-se bem adaptado ao verão, proporcionando alto rendimento em tempo relativamente curto.

Palavras-chave: Vigna radiata, rendimento, acamamento, ciclo vegetativo.

\begin{abstract}
Mungbean cultivation in summer in Viçosa and Prudente de Morais, Minas Gerais State, Brazil

We evaluated 25 genotypes of mungbean in the summer in Viçosa (sown in December 1997) and Prudente de Morais (sown in January 1999): nineteen lines from the Asian Vegetable Research Development Center, four from the Instituto Nacional de Pesquisa da Amazônia, one cv. from Peru besides cv. Ouro Verde. Yield varied from 1.2 to $2.0 \mathrm{t} / \mathrm{ha}$ in Viçosa, and from 1.3 to $2.6 \mathrm{t} / \mathrm{ha}$ in Prudente de Morais. Several lines yielded more than the cultivar Ouro Verde, standing out the line VC 3984-B-2-B-4-1-B due to the resistance to prostration. Mungbeans were well adapted in the summer season providing high yield in relatively short time.
\end{abstract}

Keywords: Vigna radiata, yield, loading, life cycle.

(Recebido para publicação em 16 de agosto de 2001 e aceito em 10 de outubro de 2002)

$\mathrm{O}$ feijão-mungo-verde ou mungoverde é importante leguminosa granífera cultivada na Ásia, sendo a Índia o maior produtor mundial, com produção, em 1995/96, de 1.374.000 t, que representaram $47 \%$ do total produzido no mundo (Tickoo \& Satyanarayana, 1998). Com a germinação de suas sementes são obtidos os brotos de feijão (moyashi), forma de consumo muito apreciada na China, no Japão e nos EUA, dentre outros países. No Brasil, a produção de mungo-verde é incipiente, mas a tendência é crescente, por causa do aumento da demanda pelo broto de feijão.

A planta é anual, de porte ereto ou semi-ereto, com caule, ramos e folhas cobertos por pêlos, e com altura que varia de 0,3 a 1,5 m. A floração tem início entre 25 e 42 dias após a emergência, dependendo da cultivar, da região e da época de plantio (Sayão et al., 1991; Vieira \& Nishihara, 1992; Miranda et al., 1996). O número de vagens por planta varia de 4 a 34, dependendo principalmente da população de plantas por área e das condições edafoclimáticas. As vagens são cilíndricas, com sete a $15 \mathrm{~cm}$ de comprimento e, em geral, são cobertas com pêlos. Na maturação, que é desuniforme, as vagens secas apresentam coloração marrom ou preta, e cada vagem contém de seis a 20 sementes. Estas são pequenas (3,5 a 7,0 g/100 unidades) e as cultivares comerciais têm tegumento de coloração verde.

A temperatura mínima média para o desenvolvimento do mungo-verde provavelmente é de $20-22^{\circ} \mathrm{C}$ e a ótima, de $28-30^{\circ} \mathrm{C}$, talvez um pouco acima se a umidade for adequada (Poehlman, 1978). O crescimento e o desenvolvimento dessa leguminosa são afetados pelos comprimento do dia, temperatura e umidade. É considerada espécie de dias curtos (Nalampang, 1992). A primeira vagem madura é observada entre 39 e 86 dias após o plantio, dependendo da cultivar e das condições climáticas (Somaatmadja \& Sutarman, 1978). Plantado em outubro ou novembro, o mungo-verde pode proporcionar várias colheitas de vagens secas, e o espaço de tempo entre a maturação da primeira vagem e a última colheita pode chegar a 50 dias, se não houver veranico em janeiro ou fevereiro. Assim, podem ser necessárias até cinco colheitas. No entanto, $70 \%$ a $80 \%$ da produção total é obtida nas primeira e segunda colheitas (Duque \& Pessanha, 1990; Vieira \& Nishihara, 1992; Vieira \& Vieira, 1996). A qualidade das sementes provenientes do plantio em outubro-novembro geralmente não é boa, pois a maturação das vagens coincide com período chuvoso. Plantado em fevereiro ou março, de preferência com irrigação para suplementar as chuvas, é possível fazer uma única colheita e, neste caso, o risco de chuva durante o período de maturação das vagens é pequeno. Conseqüentemente, as sementes colhidas, em geral, são de alta qualidade. O ciclo de vida do mungo-verde plantado nesses dois meses depende do clima. Nas regiões altas da Zona da Mata de Minas Gerais, a colheita pode ser feita com 70 dias, nos anos mais quentes; nos anos mais frios, o ciclo de vida pode prolongar-se por mais 30 dias (Vieira \& Nishihara, 1992). Nas regiões quentes, a colheita pode ser realizada aos 65 dias após o plantio (Duque et al., 1987; Duque \& Pessanha, 1990; Miranda et al., 1996). A localização alta das vagens na planta permite a 
colheita mecanizada. Neste caso, é importante que a maturação das vagens ocorra em período de estiagem e que se faça uso de dessecante, pois o mungoverde mantém a folhagem no período de maturação das vagens. $\mathrm{Na}$ Índia, o rendimento médio do mungo-verde é de $400 \mathrm{~kg} \mathrm{ha}^{-1}$; na China, na Indonésia, em Myanmar e na Tailândia é de 1.100, 800, 300 e $700 \mathrm{~kg} \mathrm{ha}^{-1}$, respectivamente (Tickoo \& Satyanarayana, 1998). Em ensaios de competição entre linhagens de mungo-verde conduzidos em Viçosa (MG) e em Itaguaí (RJ), com o plantio em outubro ou novembro, os rendimentos variaram de 135 a $2.126 \mathrm{~kg} \mathrm{ha}^{-1}$ (Duque \& Pessanha, 1990; Sayão et al., 1991; Vieira \& Nishihara, 1992; Vieira et al., 1992; Vieira \& Vieira, 1996; Nasser \& Vieira, 1997). Plantios conduzidos em fevereiro ou março, quando irrigados produziram de 805 a $1.333 \mathrm{~kg}$ ha $^{-1}$ e, quando não irrigados, produziram de 159 a $1.796 \mathrm{~kg} \mathrm{ha}^{-1}$ (Miranda et al., 1996; Duque et al., 1987; Duque \& Pessanha, 1990; Vieira \& Nishihara, 1992; Vieira et al., 1992). Em ensaio instalado em junho, em solo Gley Húmico, em Formoso do Araguaia (TO), os rendimentos variaram de 268 a $708 \mathrm{~kg} / \mathrm{ha}$ (Miranda et al., 1996). Segundo esses autores, os baixos rendimentos foram consequiência da pouca adubação e do excesso de umidade do solo. No estado do Amazonas, o mungoverde chegou a produzir $2.175 \mathrm{~kg} / \mathrm{ha}$ quando plantado em solo de várzea; em terra firme o rendimento máximo alcançado foi $1.140 \mathrm{~kg} / \mathrm{ha}$ (Yuyama, 1997). Em 1993, foi lançada a primeira cultivar de mungo-verde para Minas Gerais, denominada Ouro Verde, que apresenta o defeito de acamar com facilidade, o que tem trazido transtornos na colheita, tanto mecânica quanto manual. Portanto, urge substituí-la por cultivar com características agronômicas mais desejáveis. O objetivo desta pesquisa foi avaliar, no verão, o comportamento de novas linhagens de mungo-verde em duas regiões de Minas Gerais.

\section{MATERIAL E MÉTODOS}

Foram conduzidos dois ensaios de competição entre genótipos de mungoverde em Minas Gerais: um em Viçosa, na Zona da Mata, e outro em Prudente de Morais, no Centro-Oeste. Viçosa está a uma altitude de $640 \mathrm{~m}$; Prudente de Morais, de 732 m. Em Viçosa, o ensaio foi conduzido num PODZÓLICO Vermelho amarelo câmbico e em Prudente de Morais, num LATOSSOLO Vermelho escuro fase cerrado. O plantio foi feito em 11/12/97 e em 13/01/99, respectivamente. As temperaturas máximas e mínimas médias durante a condução do ensaio, em Viçosa, variaram de 27 a $34,6^{\circ} \mathrm{C}$ e de 19,4 a $20,3^{\circ} \mathrm{C}$, respectivamente. Em Prudente de Morais as temperaturas máximas e mínimas médias variaram de 27,5 a $31,6^{\circ} \mathrm{C}$ e de 17,3 a $20,1^{\circ} \mathrm{C}$, respectivamente.

Foram utilizadas 23 linhagens e duas cultivares (Tabela 1). A cultivar Ouro Verde, originária do Instituto Nacional de Pesquisa da Amazônia (INPA), onde tem a denominação KY 1954, foi lançada para plantio em Minas Gerais em 1993. As linhagens com iniciais KY também são originárias do INPA. A cultivar M-15 é de origem peruana. As demais linhagens foram obtidas no "Asian Vegetable Research and Development Center" (AVRDC), localizado em Formosa. Utilizou-se o delineamento experimental em blocos ao acaso, com três repetições. As parcelas constaram de duas fileiras de 5,0 $\mathrm{m}$ de comprimento, espaçadas de $0,5 \mathrm{~m}$. O ensaio foi cercado por bordadura da cultivar Ouro Verde. Foram utilizadas 25 sementes por metro, depositadas à profundidade aproximada de $5 \mathrm{~cm}$. Em Prudente de Morais foi feito desbaste para aproximadamente 15 plantas por metro aos 17 dias após a emergência (DAE) das plântulas. Em Viçosa não foi feito o desbaste. $\mathrm{Na}$ colheita, eliminou-se $0,5 \mathrm{~m}$ das extremidades das fileiras, ou seja, a área útil foi de $4 \mathrm{~m}^{2}$. Em Viçosa, foram utilizados na adubação de plantio $700 \mathrm{~kg} / \mathrm{ha}$ do formulado 4-14-8 ( $\left.-\mathrm{P}_{2} \mathrm{O}_{5}-\mathrm{K}_{2} \mathrm{O}\right)$; em Prudente de Morais, 27, 78 e $58 \mathrm{~kg} / \mathrm{ha}$ de $\mathrm{N}, \mathrm{P}_{2} \mathrm{O}_{5}$ e $\mathrm{K}_{2} \mathrm{O}$, na forma de sulfato de amônio, superfosfato simples e cloreto de potássio, respectivamente. Aos 23 DAE, foi feita adubação em cobertura com $100 \mathrm{~kg} / \mathrm{ha}$ de uréia, em Viçosa, e com $250 \mathrm{~kg} / \mathrm{ha}$ de sulfato de amônio, em Prudente de Morais. Três dias depois, em Viçosa, foi realizada uma pulverização (200 L/ha) das plantas com molibdato de sódio, na dose de $150 \mathrm{~g} / \mathrm{ha}$, em mistura com o inseticida deltametrina $(7,5 \mathrm{~g} / \mathrm{ha})$. Este foi utiliza- do, principalmente, para o controle da cigarrinha-verde (Empoasca kraemeri). Em razão de a formiga-saúva cortar as plantinhas de mungo-verde, fez-se o controle preventivo dessa praga. Em Viçosa, o controle de plantas daninhas foi realizado com enxada, enquanto em Prudente de Morais foi utilizada a mistura dos herbicidas fomesafen $(0,25 \mathrm{~kg} /$ ha) e fluazifop-p-butil (0,20 kg/ha), aplicados 14 DAE. Em ambos os ensaios foram realizadas irrigações por aspersão suplementares. A colheita foi feita pelo corte das plantas a cerca de $20 \mathrm{~cm}$ da superfície do solo. Em Viçosa, adotou-se o critério de se efetuar a colheita 9-10 dias após a maturação da primeira vagem. Em ambos os locais foram feitas as seguintes avaliações: data da emergência, data do início da floração, data do aparecimento da primeira vagem madura, acamamento, estande final, rendimento e peso de 100 grãos. Em Viçosa, ademais, foi anotada a cor da folhagem antes da colheita, e foram feitas as seguintes avaliações: percentagem de vagens secas e em maturação logo após a colheita, aspecto comercial dos grãos e percentagem de grãos mofados e escuros. Apenas em Prudente de Morais foi avaliada a altura das plantas. A data de emergência foi anotada quando $90 \%$ das plântulas emergentes estavam em posição vertical. O início de floração foi anotado quando $50 \%$ das plantas apresentavam pelo menos uma flor aberta; no caso da primeira vagem madura, quando $50 \%$ das plantas apresentavam pelo menos uma vagem de cor marrom ou preta. Para a medição da altura, foram escolhidas, ao acaso, 10 plantas em início de maturação em cada parcela. A avaliação do acamamento foi feita antes da colheita, adotando-se a seguinte escala: 1 - todas as plantas eretas; 2 todas as plantas ligeiramente inclinadas ou algumas plantas caídas; 3 - todas as plantas moderadamente inclinadas $\left(45^{\circ}\right)$ ou $25 \%$ a $50 \%$ das plantas caídas; 4 todas as plantas consideravelmente inclinadas ou $50 \%$ a $80 \%$ das plantas caídas; e 5 - todas as plantas fortemente inclinadas ou $80 \%$ a $100 \%$ das plantas caídas. A percentagem média de vagens secas e em maturação foi calculada com base em 10 plantas, escolhidas ao acaso, de cada genótipo da primeira e segunda repetições. $\mathrm{O}$ aspecto comercial dos grãos foi avaliado visualmente, levando-se em conta mancha, descoloração, 
Tabela 1. Dias para o início da floração, o aparecimento da primeira vagem madura e a colheita; cor da folhagem na colheita; e percentagem de vagens secas e em maturação em linhagens e cultivares de mungo-verde. Viçosa, Epamig, 1997.

\begin{tabular}{|c|c|c|c|c|c|c|c|}
\hline $\begin{array}{l}\text { Linhagens/ } \\
\text { cultivares }^{1}\end{array}$ & $\begin{array}{l}\text { Emergência } \\
\text { ao início da } \\
\text { floração }^{2} \\
\text { (dias) }\end{array}$ & $\begin{array}{l}\text { Emergência } \\
\text { à primeira } \\
\text { vagem ma- } \\
\text { dura }^{3} \text { (dias) }\end{array}$ & $\begin{array}{l}\text { Início da } \\
\text { floração à } \\
\text { primeira } \\
\text { vagem } \\
\text { madura }^{2,3} \\
\text { (dias) }\end{array}$ & $\begin{array}{c}\text { Emergência } \\
\text { à colheita } \\
\text { (dias) }\end{array}$ & $\begin{array}{c}\text { Cor da } \\
\text { folhagem }\end{array}$ & $\begin{array}{c}\text { Vagens } \\
\text { secas } \\
(\%)\end{array}$ & $\begin{array}{c}\text { Vagens } \\
\text { secas } \\
\text { e em } \\
\text { maturação } \\
(\%)\end{array}$ \\
\hline VC 4080A (B) & 31 & 52 & 21 & 61 & A & 73 & 91 \\
\hline VC 4059A (F) & 33 & 53 & 20 & 62 & A & 76 & 95 \\
\hline 4143A (F) & 32 & 53 & 21 & 62 & $\mathrm{AE}$ & 77 & 96 \\
\hline VC 3738A (F) & 32 & 51 & 19 & 61 & A & 78 & 96 \\
\hline VC 4049-B-3-1...(F) & 34 & 54 & 20 & 63 & $\mathrm{AE}$ & 87 & 96 \\
\hline 1893A (B) & 31 & 51 & 20 & 61 & A & 83 & 96 \\
\hline M-15 (B) & 36 & 53 & 17 & 62 & $A E$ & 61 & 90 \\
\hline V 3476 (B) & 34 & 53 & 19 & 62 & $A E$ & 51 & 80 \\
\hline VC 3984-B-2-B...(B) & 33 & 51 & 18 & 61 & $A E$ & 77 & 88 \\
\hline VC 3300A (F) & 33 & 53 & 20 & 62 & A & 68 & 95 \\
\hline VC 3061A (F) & 33 & 53 & 20 & 62 & A & 81 & 95 \\
\hline VC 4111A (F) & 36 & 56 & 20 & 65 & $\mathrm{AE}$ & 81 & 94 \\
\hline VC 3178A (B) & 36 & 55 & 19 & 64 & $\mathrm{AE}$ & 82 & 95 \\
\hline VC 3890A (F) & 35 & 54 & 19 & 63 & A & 84 & 98 \\
\hline VC 3828-1-1-1...(F) & 36 & 55 & 19 & 64 & $A E$ & 82 & 94 \\
\hline VC 3902A (B) & 35 & 55 & 20 & 64 & $A E$ & 87 & 96 \\
\hline Ouro Verde (F) & 37 & 54 & 17 & 63 & $\mathrm{AE}$ & 80 & 95 \\
\hline KY 2273 (F) & 37 & 54 & 17 & 63 & $\mathrm{AE}$ & 76 & 96 \\
\hline VC 4066A (F) & 36 & 56 & 20 & 65 & V & 84 & 96 \\
\hline KY 1945 (F) & 36 & 54 & 18 & 63 & V & 75 & 94 \\
\hline KY 2984 (B) & 38 & 57 & 19 & 66 & $\mathrm{AE}$ & 92 & 99 \\
\hline VC $2771 A(B)$ & 35 & 55 & 20 & 64 & A & 82 & 96 \\
\hline VC 2750A (F) & 35 & 55 & 20 & 64 & V & 70 & 93 \\
\hline KY 2013 (F) & 37 & 54 & 17 & 63 & $A E$ & 87 & 97 \\
\hline 1560D (B) & 37 & 56 & 19 & 65 & A & 64 & 88 \\
\hline Média & 34,7 & 53,9 & 19,2 & 63,0 & & 77,5 & 94,0 \\
\hline
\end{tabular}

1/Entre parênteses: $\mathrm{F}=$ tegumento fosco, $\mathrm{B}=$ tegumento brilhante.

2/O início da floração foi anotado quando 50\% das plantas apresentavam pelo menos uma flor aberta.

3/ A primeira vagem madura foi anotada quando $50 \%$ das plantas apresentavam pelo menos uma vagem marrom ou preta.

4/ A colheita foi feita aos nove ou 10 dias após a maturação da primeira vagem.

5/ Observação feita no dia da colheita: $\mathrm{A}=$ amarela; $\mathrm{AE}=$ amarelado-esverdeada; $\mathrm{V}=$ verde.

enrugamento e uniformidade de coloração dos grãos, com base na seguinte escala arbitrária: 1 - ótimo, 2 - bom, 3 regular, 4 -ruim e 5 - péssimo. A percentagem de grãos mofados e escuros foi avaliada em amostra de 100 grãos, escolhidos ao acaso, de cada parcela.

Os dados de altura de planta, de acamamento, de estande final, de rendimento, de peso de 100 grãos, de aspecto comercial dos grãos, de grãos mofados e de grãos escuros foram submetidos à analise de variância. Foi utilizado o teste de Scott-Knott, a 5\% de probabilidade, para o agrupamento das médias.

\section{RESULTADOS E DISCUSSÃO}

\section{Ensaio de Viçosa}

A emergência das plântulas ocorreu sete dias após o plantio e, entre 31 e 38 DAE, as plantas iniciaram o florescimento (Tabela 1). Os genótipos apresentaram a primeira vagem madura entre 51 e 57 DAE. A linhagem 1560D foi a única que não apresentou pilosidade nas vagens, característica desejável, visto que torna a colheita manual das vagens mais confortável. As linhagens VC 3738A, 1893A e VC 3984-B-2-B-4-1-B foram as mais precoces. O tempo entre o início da floração e o aparecimento da primeira vagem 
Tabela 2. Acamamento, estande final, rendimento, peso e aspecto comercial dos grãos, e percentagem de grãos mofados e escuros em linhagens e cultivares de mungo-verde. Viçosa, Epamig, 1997.

\begin{tabular}{|c|c|c|c|c|c|c|c|}
\hline $\begin{array}{l}\text { Linhagens/ } \\
\text { cultivares }^{2}\end{array}$ & $\begin{array}{l}\text { Acama- } \\
\text { mento }^{3}\end{array}$ & $\begin{array}{c}\text { Estande } \\
\text { final } \\
\left(4 \mathrm{~m}^{2}\right)\end{array}$ & $\begin{array}{l}\text { Rendimen- } \\
\text { to }\left(\mathrm{t} \mathrm{ha}^{-1}\right)\end{array}$ & $\begin{array}{l}\text { Peso de } 100 \\
\text { grãos (g) }\end{array}$ & $\begin{array}{c}\text { Aspecto } \\
\text { comercial } \\
\text { dos grãos }\end{array}$ & $\begin{array}{c}\text { Grãos } \\
\text { mofados }^{5} \\
\text { (\%) }\end{array}$ & $\begin{array}{c}\text { Grãos } \\
\text { escuros } \\
(\%)\end{array}$ \\
\hline VC 4080A (B) & $3,8 a^{*}$ & 99,7 & $2,0 \mathrm{a}$ & $7,0 \mathrm{~b}$ & $2,2 \mathrm{c}$ & $0,3 c$ & $18,7 \mathrm{~d}$ \\
\hline VC 4059A (F) & $4,5 \mathrm{a}$ & 135,0 & $2,0 \mathrm{a}$ & $6,4 \mathrm{~b}$ & $4,0 \mathrm{a}$ & $10,3 b$ & $27,7 \mathrm{c}$ \\
\hline $4143 A(F)$ & 4,3 a & 158,7 & $1,8 \mathrm{a}$ & $5,5 d$ & $4,0 \mathrm{a}$ & $10,7 \mathrm{~b}$ & $54,3 \mathrm{~b}$ \\
\hline VC 3738A (F) & $4,2 \mathrm{a}$ & 144,0 & $1,8 \mathrm{a}$ & $5,6 \mathrm{~d}$ & $3,2 \mathrm{~b}$ & $8,7 \mathrm{~b}$ & $34,0 \mathrm{c}$ \\
\hline VC 4049-B-3-1... (F) & $4,2 \mathrm{a}$ & 114,0 & $1,8 \mathrm{a}$ & $6,6 \mathrm{~b}$ & $3,2 \mathrm{~b}$ & $12,7 \mathrm{~b}$ & $77,0 \mathrm{a}$ \\
\hline $1893 \mathrm{~A}(\mathrm{~B})$ & $5,0 \mathrm{a}$ & 106,7 & $1,8 \mathrm{a}$ & $6,5 \mathrm{~b}$ & $3,2 b$ & $6,0 \mathrm{c}$ & $39,0 \mathrm{c}$ \\
\hline M-15 (B) & 5,0 a & 113,7 & $1,8 \mathrm{a}$ & $6,1 \mathrm{c}$ & $4,0 \mathrm{a}$ & $5,3 \mathrm{c}$ & $29,7 \mathrm{c}$ \\
\hline V 3476 (B) & 3,7 a & 107,3 & $1,8 \mathrm{a}$ & $5,2 \mathrm{e}$ & $3,2 b$ & $1,7 \mathrm{c}$ & $30,0 \mathrm{c}$ \\
\hline VC 3984-B-2-B... (B) & $1,7 \mathrm{c}$ & 119,0 & $1,7 \mathrm{a}$ & $5,0 \mathrm{e}$ & $2,5 \mathrm{c}$ & $3,0 \mathrm{c}$ & $11,0 d$ \\
\hline VC $3300 A(F)$ & $4,2 \mathrm{a}$ & 140,3 & $1,7 \mathrm{a}$ & $6,5 \mathrm{~b}$ & $4,0 \mathrm{a}$ & $21,7 \mathrm{a}$ & $60,0 \mathrm{~b}$ \\
\hline VC 3061A (F) & 4,7 a & 140,0 & $1,7 \mathrm{a}$ & $6,2 \mathrm{c}$ & $3,7 \mathrm{a}$ & $16,7 \mathrm{a}$ & 68,7 a \\
\hline VC 4111A (F) & 4,3 a & 136,7 & $1,7 \mathrm{a}$ & $5,4 d$ & $4,2 \mathrm{a}$ & $1,7 \mathrm{c}$ & $59,0 \mathrm{~b}$ \\
\hline VC 3178A (B) & $2,8 \mathrm{~b}$ & 135,7 & $1,6 \mathrm{a}$ & $6,2 \mathrm{c}$ & $3,0 \mathrm{~b}$ & $0,0 \mathrm{c}$ & $30,3 \mathrm{c}$ \\
\hline VC $3890 A(F)$ & $4,3 \mathrm{a}$ & 114,7 & $1,6 \mathrm{a}$ & $6,6 \mathrm{~b}$ & $3,8 \mathrm{a}$ & $13,7 b$ & $28,0 \mathrm{c}$ \\
\hline VC 3828-1-1-1... (F) & $2,8 \mathrm{~b}$ & 116,3 & $1,6 \mathrm{a}$ & $6,6 \mathrm{~b}$ & $2,5 \mathrm{c}$ & $3,7 \mathrm{c}$ & 87,7 a \\
\hline VC 3902A (B) & $4,8 \mathrm{a}$ & 118,7 & $1,6 \mathrm{a}$ & $7,8 \mathrm{a}$ & $3,7 \mathrm{a}$ & $4,0 \mathrm{c}$ & $33,3 \mathrm{c}$ \\
\hline Ouro Verde (F) & $5,0 \mathrm{a}$ & 128,7 & $1,6 b$ & $5,1 \mathrm{e}$ & 4,3 a & $34,0 \mathrm{a}$ & $53,3 b$ \\
\hline KY $2273(F)$ & $5,0 \mathrm{a}$ & 148,0 & $1,5 b$ & $4,8 \mathrm{e}$ & $3,8 \mathrm{a}$ & $19,0 \mathrm{a}$ & $42,7 \mathrm{c}$ \\
\hline VC 4066A (F) & $4,3 \mathrm{a}$ & 137,7 & $1,5 b$ & $6,7 \mathrm{~b}$ & $4,2 \mathrm{a}$ & $4,7 \mathrm{c}$ & $72,0 \mathrm{a}$ \\
\hline KY $1945(F)$ & $4,5 \mathrm{a}$ & 135,3 & $1,5 b$ & $4,3 f$ & $3,8 \mathrm{a}$ & $1,7 \mathrm{c}$ & $54,7 \mathrm{~b}$ \\
\hline KY 2984 (B) & $3,8 \mathrm{a}$ & 99,0 & $1,4 \mathrm{~b}$ & $5,0 \mathrm{e}$ & $3,3 b$ & $8,3 \mathrm{~b}$ & $39,3 \mathrm{c}$ \\
\hline VC $2771 A(B)$ & $4,7 \mathrm{a}$ & 123,3 & $1,4 \mathrm{~b}$ & $6,3 c$ & $4,0 \mathrm{a}$ & 20,0 a & $45,3 \mathrm{c}$ \\
\hline VC $2750 A(F)$ & 4,7 a & 113,7 & $1,3 b$ & $6,4 \mathrm{c}$ & $4,0 \mathrm{a}$ & $11,0 \mathrm{~b}$ & $72,0 \mathrm{a}$ \\
\hline KY 2013 (F) & $4,5 \mathrm{a}$ & 165,7 & $1,2 \mathrm{~b}$ & 5,1 e & $3,7 \mathrm{a}$ & $1,7 \mathrm{c}$ & $56,7 \mathrm{~b}$ \\
\hline 1560D (B) & $4,8 \mathrm{a}$ & 88,0 & $1,2 \mathrm{~b}$ & $6,2 \mathrm{c}$ & $4,0 \mathrm{a}$ & $8,3 \mathrm{~b}$ & $50,7 \mathrm{~b}$ \\
\hline Média & 4,2 & 125,6 & 1,6 & 6,0 & 3,6 & 9,2 & 47,0 \\
\hline C.V. (\%) & 15,6 & 20,1 & 12,5 & 4,0 & 12,2 & 36,8 & 16,1 \\
\hline
\end{tabular}

* Em cada coluna, as médias com letras iguais pertencem ao mesmo grupo, pelo teste de Scott-Knott a 5\% de probabilidade.

2/Entre parênteses: $\mathrm{F}=$ tegumento fosco, $\mathrm{B}=$ tegumento brilhante.

$3 / 1=$ todas as plantas eretas; $2=$ todas as plantas ligeiramente inclinadas ou algumas plantas caídas; $3=$ todas as plantas moderadamente inclinadas $\left(45^{\circ}\right)$ ou $25 \%$ a $50 \%$ das plantas caídas; 4 = todas as plantas consideravelmente inclinadas ou $50 \%$ a $80 \%$ das plantas caídas; e 5 $=$ todas as plantas fortemente inclinadas ou $80 \%$ a $100 \%$ das plantas caídas.

4/ 1 = ótimo, 2 = bom, 3 = regular, 4 = ruim e 5 = péssimo.

5/ Dados previamente transformados em arcsen $\sqrt{\%}$ para a realização da análise de variância.

madura variou de 17 a 21 dias. Em geral, esse período reprodutivo foi mais curto nos genótipos não originados do AVRDC, como as cultivares M-15 e Ouro Verde e as linhagens KY 2273, KY 1945 e KY 2013.

As colheitas foram realizadas entre 61 e 66 DAE. No dia da colheita, a maioria dos genótipos apresentava folhagem amarela ou amarelo-esverdeada; apenas três mantiveram a cor verde (Tabela 1). A primeira situação é desejável, porquanto há menos risco de fermentação das plantas quando, após a colheita em período chuvoso, elas são amontoadas a espera de dia ensolarado para a finalização da secagem. No estudo de Vieira \& Nishihara (1992), a linhagem VC 3061A também esteve entre as que apresentavam folhagem amarela durante a colheita. Dependendo do genótipo, entre $51 \%$ e $92 \%$ das vagens estavam secas no dia da colheita e, quando foram incluídas as vagens em maturação, a variação passou a ser de $80 \%$ a $99 \%$. Essa maturação foi mais uniforme que a verificada por Vieira \& Nishihara (1992) quando o plantio foi feito em novembro. A linhagem KY 2984 apresentou maturação mais uniforme; no 
Tabela 3. Dias para o início da floração e o aparecimento da primeira vagem madura em linhagens e cultivares de mungo-verde. Prudente de Morais, Epamig, 1999.

\begin{tabular}{|c|c|c|c|}
\hline Linhagens/cultivares $^{1}$ & $\begin{array}{l}\text { Emergência ao início da } \\
\text { floraçãoº (dias) }\end{array}$ & $\begin{array}{l}\text { Emergência à primeira } \\
\text { vagem madura }{ }^{3} \text { (dias) }\end{array}$ & $\begin{array}{l}\text { Início da floração à } \\
\text { primeira vagem madura } \\
\text { (dias) }\end{array}$ \\
\hline VC 4059A (F) & 33 & 56 & 23 \\
\hline $4143 \mathrm{~A}(\mathrm{~F})$ & 32 & 58 & 26 \\
\hline VC 4049-B-3-1-1-1-B (F) & 32 & 55 & 23 \\
\hline V 3476 (B) & 32 & 57 & 25 \\
\hline VC 3890A (F) & 32 & 58 & 26 \\
\hline VC 3828-1-1-1-1-B (F) & 33 & 57 & 24 \\
\hline VC 4066A (F) & 35 & 58 & 23 \\
\hline VC 3178A (B) & 36 & 58 & 22 \\
\hline VC 4111A (F) & 35 & 55 & 20 \\
\hline KY $2013(F)$ & 35 & 55 & 20 \\
\hline VC $2771 A(B)$ & 34 & 56 & 22 \\
\hline VC $3300 A(F)$ & 32 & 57 & 25 \\
\hline $1893 \mathrm{~A}(\mathrm{~B})$ & 31 & 57 & 26 \\
\hline VC 3061A (F) & 33 & 56 & 23 \\
\hline VC 3738A (F) & 32 & 58 & 26 \\
\hline VC 3902A (B) & 33 & 58 & 25 \\
\hline VC 2750A (F) & 35 & 58 & 23 \\
\hline VC 3984-B-2-B-4-1-B (B) & 33 & 55 & 23 \\
\hline KY 2984 (B) & 38 & 60 & 22 \\
\hline Ouro Verde (F) & 35 & 55 & 20 \\
\hline VC 4080A (B) & 32 & 55 & 23 \\
\hline KY 2273 (F) & 36 & 57 & 21 \\
\hline M-15 (B) & 35 & 57 & 22 \\
\hline 1560D (B) & 34 & 58 & 24 \\
\hline KY $1945(F)$ & 37 & 58 & 21 \\
\hline Média & 33,8 & 56,9 & 23,1 \\
\hline
\end{tabular}

1/Entre parênteses: $\mathrm{F}=$ tegumento fosco, $\mathrm{B}=$ tegumento brilhante.

2/ O início da floração foi anotado quando $50 \%$ das plantas apresentavam pelo menos uma flor aberta.

3/ A primeira vagem madura foi anotado quando $50 \%$ das plantas apresentavam pelo menos uma vagem marrom ou preta.

outro extremo ficou a linhagem V 3476.

Em geral, os genótipos acamaram bastante (Tabela 2). As exceções ocorreram com as linhagens VC 3178A, VC 3828-1-1-1-1-B e, principalmente, com a VC 3984-B-2-B-4-1-B. Esta última também esteve entre as que não acamaram no estudo de Vieira \& Nishihara (1992). Não houve diferença significativa entre as médias do estande final. Com base nos resultados de estudo de densidade de plantio obtidos por Miranda et al. (1997) com essa leguminosa, acredita-se que a variação de população de plantas (220 a 414 mil plantas/ha) entre genótipos, neste ensaio, não tenha influenciado o rendimento de grãos. O rendimento médio alcançado foi de $1.631 \mathrm{~kg} \mathrm{ha}^{-1}$, e as linhagens com médias iguais ou acima de 1.621 $\mathrm{kg} \mathrm{ha}^{-1}$ ficaram no grupo das mais produtivas (Tabela 2). A cultivar Ouro Verde (KY 1954) ficou no grupo das menos produtivas, assim como todas as linhagens originadas do INPA (com iniciais KY). A linhagem VC 3902A, de tegumento brilhante, apresentou os grãos mais pesados $(7,8 \mathrm{~g} / 100$ unidades); no outro extremo ficou a linhagem KY 1945 (4,3 g/100 unidades), de tegumento fosco. $\mathrm{O}$ aspecto comercial dos grãos foi prejudicado pelas chuvas que ocorreram durante o período de maturação das vagens. As linhagens que tiveram os grãos pouco afetados foram VC 4080A, VC 3984-B-2-B-4-1-B e VC 3828-1-1-1-1-B. Estas também estiveram entre as que apresentaram menos grãos mofados. A VC 3828-1-1-1-1-B, ao contrário da VC 3984-B-2-B-4-1-B e da VC 4080A, apresentou alta percentagem de grãos escuros. Esta característica indesejável foi observada com maior intensidade nas linhagens com grãos foscos. 
Tabela 4. Altura de plantas, acamamento, estande final, rendimento e peso de grãos em linhagens e cultivares de mungo-verde. Prudente de Morais, Epamig, 1999.

\begin{tabular}{|c|c|c|c|c|c|}
\hline $\begin{array}{l}\text { Linhagens/ } \\
\text { cultivares }^{2}\end{array}$ & $\begin{array}{c}\text { Altura de } \\
\text { plantas }(\mathbf{c m})\end{array}$ & Acamamento $^{3}$ & $\begin{array}{l}\text { Estande final } \\
\qquad\left(4 \mathrm{~m}^{2}\right)\end{array}$ & $\begin{array}{l}\text { Rendimento } \\
\text { (kg/ha) }\end{array}$ & $\begin{array}{c}\text { Peso de } 100 \\
\text { grãos (g) }\end{array}$ \\
\hline VC 4059A (F) & $85 c^{*}$ & $5,0 \mathrm{a}$ & 115,3 & $2.550 \mathrm{a}$ & $5,5 \mathrm{~b}$ \\
\hline 4143A (F) & $87 \mathrm{c}$ & $4,7 \mathrm{a}$ & 114,0 & $2.536 \mathrm{a}$ & $4,7 \mathrm{c}$ \\
\hline VC 4049-B-3-1-1-1-B (F) & $78 \mathrm{~d}$ & $4,7 \mathrm{a}$ & 112,3 & $2.501 \mathrm{a}$ & $5,0 \mathrm{c}$ \\
\hline V 3476 (B) & $78 \mathrm{~d}$ & $5,0 \mathrm{a}$ & 112,7 & $2.435 \mathrm{a}$ & $5,1 \mathrm{c}$ \\
\hline VC 3890A (F) & 69 e & $5,0 \mathrm{a}$ & 112,3 & $2.280 \mathrm{a}$ & $5,7 \mathrm{~b}$ \\
\hline VC 3828-1-1-1-1-B (F) & $95 \mathrm{~b}$ & 5,0 a & 105,0 & $2.267 \mathrm{a}$ & $5,6 \mathrm{~b}$ \\
\hline VC 4066A (F) & $77 \mathrm{~d}$ & $4,7 \mathrm{a}$ & 101,0 & $2.247 \mathrm{a}$ & $5,5 \mathrm{~b}$ \\
\hline VC 3178A (B) & $81 \mathrm{~d}$ & 5,0 a & 118,7 & $2.233 \mathrm{a}$ & $4,8 \mathrm{c}$ \\
\hline VC $4111 \mathrm{~A}(\mathrm{~F})$ & $79 \mathrm{~d}$ & $4,3 \mathrm{~b}$ & 106,0 & $2.224 a$ & $4,8 \mathrm{c}$ \\
\hline KY $2013(F)$ & $92 \mathrm{~b}$ & $5,0 \mathrm{a}$ & 109,7 & $2.186 a$ & $4,2 \mathrm{~d}$ \\
\hline VC $2771 A(B)$ & $77 \mathrm{~d}$ & $5,0 \mathrm{a}$ & 108,3 & $2.149 \mathrm{a}$ & $5,4 \mathrm{~b}$ \\
\hline VC $3300 A(F)$ & $77 \mathrm{~d}$ & 5,0 a & 110,0 & $2.142 \mathrm{a}$ & $5,6 \mathrm{~b}$ \\
\hline $1893 A(B)$ & $79 \mathrm{~d}$ & $5,0 \mathrm{a}$ & 113,7 & $2.135 \mathrm{a}$ & $5,2 \mathrm{c}$ \\
\hline VC 3061A (F) & $82 \mathrm{~d}$ & $4,0 \mathrm{~b}$ & 108,7 & $2.133 \mathrm{a}$ & $4,6 \mathrm{~d}$ \\
\hline VC 3738A (F) & 73 e & $5,0 \mathrm{a}$ & 105,0 & $2.114 \mathrm{a}$ & $5,1 \mathrm{c}$ \\
\hline VC $3902 A(B)$ & $85 \mathrm{c}$ & $5,0 \mathrm{a}$ & 104,0 & $2.056 \mathrm{a}$ & $6,5 \mathrm{a}$ \\
\hline VC $2750 A(F)$ & $86 \mathrm{c}$ & $5,0 \mathrm{a}$ & 117,0 & $2.044 \mathrm{a}$ & $5,1 \mathrm{c}$ \\
\hline VC 3984-B-2-B-4-1-B (B) & $93 \mathrm{~b}$ & $1,3 \mathrm{c}$ & 115,3 & $2.027 \mathrm{a}$ & $4,3 d$ \\
\hline KY 2984 (B) & $91 \mathrm{~b}$ & 5,0 a & 94,7 & $1.876 \mathrm{~b}$ & $3,6 \mathrm{e}$ \\
\hline Ouro Verde (F) & $115 a$ & $5,0 \mathrm{a}$ & 111,0 & $1.808 b$ & $3,5 \mathrm{e}$ \\
\hline VC $4080 A(B)$ & $78 \mathrm{~d}$ & $5,0 \mathrm{a}$ & 93,7 & $1.783 b$ & $6,2 \mathrm{a}$ \\
\hline KY $2273(F)$ & $90 \mathrm{~b}$ & $4,0 \mathrm{~b}$ & 110,3 & $1.625 \mathrm{~b}$ & $4,0 d$ \\
\hline$M-15(B)$ & $83 \mathrm{c}$ & $5,0 \mathrm{a}$ & 94,3 & $1.533 \mathrm{~b}$ & $5,3 \mathrm{c}$ \\
\hline $1560 \mathrm{D}(\mathrm{B})$ & $70 \mathrm{e}$ & $4,7 \mathrm{a}$ & 109,0 & $1.532 \mathrm{~b}$ & $5,3 \mathrm{c}$ \\
\hline KY $1945(F)$ & $122 a$ & $5,0 \mathrm{a}$ & 104,3 & $1.321 \mathrm{~b}$ & $3,6 \mathrm{e}$ \\
\hline Média & 108,3 & 4,7 & 108,3 & $2.069,5$ & 5,0 \\
\hline C.V. (\%) & 5,9 & 6,0 & 7,7 & 12,9 & 6,9 \\
\hline
\end{tabular}

* Em cada coluna, as médias com letras iguais pertencem ao mesmo grupo, pelo teste de Scott-Knott a 5\% de probabilidade.

2/Entre parênteses: $\mathrm{F}=$ tegumento fosco, $\mathrm{B}=$ tegumento brilhante.

$3 / 1=$ todas as plantas eretas; $2=$ todas as plantas ligeiramente inclinadas ou algumas plantas caídas; $3=$ todas as plantas moderadamente inclinadas $\left(45^{\circ}\right)$ ou $25 \%$ a $50 \%$ das plantas caídas; $4=$ todas as plantas consideravelmente inclinadas ou $50 \%$ a $80 \%$ das plantas caídas; e 5 $=$ todas as plantas fortemente inclinadas ou $80 \%$ a $100 \%$ das plantas caídas.

A correlação significativa entre acamamento e aspecto comercial dos grãos $(\mathrm{r}=0,72 * *)$ confirma a hipótese de que cultivares que acamam mais têm mais vagens em contato com o solo e, consequentemente, quando o solo está úmido no período de maturação da leguminosa, as sementes podem ser mais prejudicadas que as provenientes de cultivares que acamam pouco. A correlação entre acamamento e percentagem de grãos mofados $\left(r=0,43^{*}\right)$, e a entre esta última variável e aspecto comercial dos grãos $\left(r=0,48^{*}\right)$, indicam que um dos efeitos da maior umidade a que os grãos ficaram expostos, dentro das vagens úmidas de plantas acamadas, foi o aumento de grãos mofados. As correlações entre percentagem de grãos escuros e acamamento, e entre aquela variável e aspecto comercial dos grãos, não foram significativas.

\section{Ensaio de Prudente de Morais}

A emergência das plântulas ocorreu aos sete dias após o plantio. Em média, o início da floração (Tabela 3) aconteceu um pouco mais cedo que em Viçosa (Tabela 1), talvez porque as temperatu- ras, que ocorreram durante o período vegetativo, tenham sido um pouco mais altas que em Viçosa. O contrário ocorreu em relação ao aparecimento da primeira vagem madura, em razão do tempo entre o início da floração e o aparecimento da primeira vagem madura, que foi em média quase quatro dias mais longo que no ensaio de Viçosa. Acredita-se que esse período reprodutivo tenha se prolongado neste ensaio porque ele coincidiu com período de temperaturas mais amenas (20/02 - 18/03), em relação ao ensaio de Viçosa (20/01 - 10/02). 
A linhagem VC 3984-B-2-B-4-1-B foi novamente uma das mais precoces. Novamente, os genótipos não originados do AVRDC apresentaram período mais curto entre o início da floração e o aparecimento da primeira vagem madura. A colheita foi feita aos $77 \mathrm{DAE}$, quando a maioria das vagens de todos os genótipos estava seca.

A cultivar Ouro Verde e a linhagem KY 1945 apresentaram as plantas mais altas, 115 e $122 \mathrm{~cm}$, respectivamente (Tabela 4). No outro extremo ficaram as linhagens VC 3890A (69 cm), 1560D $(70 \mathrm{~cm})$ e VC $3738 \mathrm{~A}(73 \mathrm{~cm})$. No geral, o acamamento foi maior neste ensaio que no anterior. Diferentemente do ensaio de Viçosa, apenas a linhagem VC 3984-B-2-B-4-1-B apresentou alta resistência ao acamamento. Não houve efeito significativo de estande final, que variou de 93,7 plantas $/ 4 \mathrm{~m}^{2}$ (234 mil plantas ha $\left.{ }^{-1}\right)$ a 118,7 plantas $/ 4 m^{2}(297$ mil plantas ha ${ }^{-1}$ ). Três linhagens (VC 4059A, 4143A e VC 4049-B-3-1-1-1B) proporcionaram rendimentos acima de $2.500 \mathrm{~kg} \mathrm{ha}^{-1}$, médias que ainda não haviam sido alcançadas no Brasil (Duque et al., 1987; Duque \& Pessanha, 1990; Sayão et al., 1991; Vieira \& Nishihara, 1992; Vieira et al., 1992; Miranda et al., 1996; Vieira \& Vieira, 1996; Nasser \& Vieira, 1997; Yuyama, 1997). No entanto, elas ficaram no mesmo grupo de rendimento de outras 15 linhagens, todas com médias superiores a $2.000 \mathrm{~kg} / \mathrm{ha}$ (Tabela 4). Também neste ensaio, a cultivar 'Ouro Verde' e algumas linhagens originadas do INPA ficaram no grupo das menos produtivas. $\mathrm{O}$ peso de 100 grãos ficou, em média, $1 \mathrm{~g}$ abaixo do verificado em Viçosa (Tabela 2). As linhagens com os grãos mais pesados foram a VC 3902A (6,5 g/100 unidades) e a VC 4080A (6,2 g/100 unidades), enquanto os genótipos originados do INPA, KY 2984, Ouro Verde e KY 1945, apresentaram o menor peso de 100 grãos (3,5 ou 3,6 g/100 unidades).

Com base nos resultados obtidos neste estudo, pode-se afirmar que o feijão-mungo-verde é bem adaptado ao verão, proporcionando altos rendimentos em tempo relativamente curto. As linhagens que mais se destacaram foram as VC 4080A, VC 4059A, 4143A e VC 3984-B-2-B-4-1-B. Esta última linhagem foi a única resistente ao acamamento.

\section{AGRADECIMENTOS}

Os autores agradecem à Fundação de Amparo à Pesquisa de Minas Gerais (Fapemig) pelo financiamento do projeto que deu origem a este artigo.

\section{LITERATURA CITADA}

DUQUE, F.F.; PESSANHA, G.G. Comportamento de dez cultivares de mungo-verde nos períodos das águas e da seca em condições de campo. Pesquisa Agropecuária Brasileira, Brasília, v. 25, n. 7, p. 963-969, 1990.

DUQUE, F.F.; PESSANHA, G.G.; QUEIROZ, P.H.S. Estudo preliminar sobre o comportamento de 21 cultivares de feijão-mungo em Itaguaí, RJ. Pesquisa Agropecuária Brasileira, Brasília, v.22, n. 6, p. 593-598, 1987.

MIRANDA, G.V.; SANTOS, I.C.; PELUZIO, J.M.; BESSA, J.C.A.; COIMBRA, R.R. Comportamento de linhagens de feijão-mungo no sul do Estado do Tocantins. Horticultura Brasileira, Brasília, v. 14, n. 2, p. 148-151, 1996.
MIRANDA, G.V.; SANTOS, I.C.; PELUZIO, J.M.; SANTOS, G.R. Avaliação do feijão-mungo (Vigna radiata (L.) Wilczeck) e do feijão-arroz (Vigna umbellata (Thunb.) Ohwi \& Ohashi) em diferentes populações de plantas. Revista Ceres, v. 44, n. 251, p. 241-248, 1997.

NALAMPANG, A. Grain legumes in the tropics. Bangkok: Departament of Agriculture, 1992. 98 p. NASSER, L.C.B.; VIEIRA, R.F. Desempenho de espécies de Phaseolus e Vigna no cerrado de Planaltina, DF. Científica, Jaboticabal, v. 25, n. 1, p. 223-227, 1997.

POEHLMAN, J.M. What we have learned from the International Mungbean Nurseries. In: INTERNATIONAL MUNGBEAN SYMPOSIUM,

1., 1978, Los Baños, Philippines. Proceedings... Taipei, Taiwan: AVRDC, 1978. p. 97-100.

SAYÃO, F.A.D.; BRIOSO, P.S.T.; DUQUE, F.F. Comportamento de linhagens de mungo verde em condições de campo em Itaguaí, RJ. Pesquisa Agropecuária Brasileira, Brasília, v. 26, n. 5, p. 659-664, 1991.

SOMAATMADJA, S.; SUTARMAN, T. Present status of mungbean breeding in Indonesia. In: INTERNATIONAL MUNGBEAN SYMPOSIUM, 1., 1978, Los Baños, Philippines. Proceedings... Taipei, Taiwan: AVRDC, 1978. p. 230-232.

TICKOO, J.L.; SATYANARAYANA, A. Progress in mungbean breeding research with special emphasis on disease and insect resistance, constraints, and future directions. In: INTERNATIONAL CONSULTATION WORKSHOP ON MUNGBEAN, 1997, New Delhi, Índia. Proceedings... Tainan, Taiwan: AVRDC, 1998. p. 58-77.

VIEIRA, R.F.; NISHIHARA, M.K. Comportamento de cultivares de mungo-verde (Vigna radiata) em Viçosa, Minas Gerais. Revista Ceres, Viçosa, v. 39, n. 221, p. 60-83, 1992.

VIEIRA, R.F.; VIEIRA, C. Comportamento de feijões dos gêneros Vigna e Phaseolus no consórcio com milho plantado simultaneamente. Pesquisa Agropecuária Brasileira, Brasília, v. 31, n. 11, p. 781-787, 1996.

VIEIRA, R.F.; VIEIRA, C.; ANDRADE, G.A. Comparações agronômicas de feijões dos gêneros Vigna e Phaseolus com o feijão-comum (Phaseolus vulgaris L.). Pesquisa Agropecuária Brasileira, Brasília, v. 27, n. 6, p. 841-850, 1992. YUYAMA, K. Feijão-moyashi. In: CARDOSO, M.O., coord. Hortaliças não-convencionais da Amazônia. Brasília: SPI-Embrapa, 1997. p. 53-61. 